\title{
Factors Influencing the Intention to Quit Drinking Alcohol Among African American/Black Pregnant Women
}

\author{
Tamarra C. Jones ${ }^{1}$, Naomi Modeste ${ }^{1}$, Barbara Anderson ${ }^{2}$, Jerry Lee1, V. Joyce Lim ${ }^{1}$ \\ ${ }^{1}$ Loma Linda University \\ ${ }^{2}$ Seattle University College of Nursing
}

\begin{abstract}
Factors influencing the intention to quit drinking alcohol among pregnant African American/Black women in San Bernardino and Riverside counties, California were investigated using the theory of planned behavior. Qualitative data were collected via focus groups from 22 pregnant women to ascertain behavioral outcomes, normative, and control beliefs associated with drinking during pregnancy. These data were used to develop a quantitative questionnaire. One hundred forty eight questionnaires were analyzed. Most of the women (86\%) reported current alcohol use and $14 \%$ were former users. When adjusted for attenuation the correlation of intention with perceived control was .89 , attitude .80 , and subjective norm .77 all of which were statistically significant. The prediction of these three from their underlying beliefs provides insight into factors which may need to be changed to reduce alcohol use by pregnant African American/ Black women.
\end{abstract}

(C) 2007 Californian Journal of Health Promotion. All rights reserved.

Keywords: African American, pregnant women, intentions, quit drinking alcohol

\section{Introduction}

Alcohol abuse is a major public health issue that has no socioeconomic, ethnic, educational, or geographic boundaries. It is a leading cause of morbidity, premature mortality, and loss of productivity (National Center on Addiction and Substance Abuse [CASA], 2000). Alcohol consumption among women of childbearing age is of particular concern because of the potential consequences to the offspring. Alcohol use during pregnancy is associated with serious health consequences that can last well beyond the perinatal period. It has been linked to pregnancy complications, preterm delivery, stillbirth, neonatal death, neonatal withdrawal, sudden infant death syndrome, Fetal Alcohol Syndrome (FAS), Fetal Alcohol Effects (FAE), growth retardation, developmental delays, behavioral problems, anxiety disorders, and physical abnormalities (Cosden \& Peerson, 1997; Gittler \& McPherson, 1990; Hutchins, 1997; Ondersma, Simpson, Brestan, \& Ward, 2000; Ostrea, Brady, Gause, Raymundo, \& Stevens, 1992).
According to estimates by the Substance Abuse and Mental Health Services Agency, SAMHSA (2002), approximately $45 \%$ of all childbearing age women and nearly $40 \%$ of African American women reported alcohol consumption in the month preceding the national SAMHSA survey on drug use and health. Data from the 2001 California health interview survey indicates that approximately $44 \%$ of African American women 18-45 in the Inland Empire (comprising the South Western areas of Riverside and San Bernardino counties) report drinking in the month prior to the survey, compared to $54 \%$ for the State. Vega, Noble, Kolody, Porter, Hwang, \& Bole (1992) conducted a study designed to obtain an accurate estimate of the number of California infants prenatally exposed to alcohol and/or other drugs. The study utilized urine analysis of women in active labor to determine prenatal exposure. The overall State prevalence rate for alcohol use was $6.7 \%$. The rate for African American/Black women was almost double the State prevalence rate at $11.6 \%$. Since 1992 there has not been an equivalent study conducted in California. According to McMillan and Conner (2003) ten 
studies were conducted in the 1990's that applied the theory of planned behavior to alcohol use. McMillan and Conner conducted a study to gain understanding about alcohol and tobacco use in college students. They reported that intentions were significantly correlated with attitude and perceived behavioral control. The authors reported that "attitude, subjective norm, and perceived behavioral control account for an average of $41 \%$ of the variance in intention to drink alcohol" (McMillan \& Conner, 2003, p. 318). A study conducted by Johnston and White, 2003, used the theory of planned behavior to assess binge drinking in undergraduates. According to the authors, attitude, subjective norm, and perceived behavioral control were predictive of binge drinking intentions. Both studies provide further support for the efficacy of the theory of planned behavior in predicting behaviors associated with drinking.

African Americans are disproportionately affected by fetal alcohol exposure. African Americans have the second highest incidence of FAS in the United States. Only Native Americans have higher incidence (Abel, 1995; Checky, n.d.). In addition, FAS incidence among African Americans is estimated to be seven to ten times higher than in Caucasian counterparts (Abel, 1995; Checky, n.d.; Graves, 2002; May \& Gossage, 2001; National Institute on Alcohol Abuse \& Alcoholism, 1994).

Caetano, Clark and Tam (1998) found that a complicated mesh of individual attributes, environmental factors, and cultural characteristics affect a person's decision to quit drinking. Approximately two-thirds of women who report drinking alcohol prior to pregnancy spontaneously quit upon recognition of their pregnancy status (Curry, Grothaus, Lando, McBride, \& Pirie, 2000; Day, Goldschmidt \& Lucas, 2003; Ockene, Ma, Pbert, Goins, \& Stoddard Zapka, 2002). Many factors contribute to abstinence. One factor that may influence sobriety during pregnancy is a woman's ethnic cultural background. Compared to Caucasian women, African American/Black women are more likely to continue drinking throughout pregnancy (Lucas et al., 2003).
A limited number of research studies have addressed alcohol consumption patterns among women of different ethnicities. Ethnic differences influence social norms and beliefs; cultural differences, religious practices and beliefs, and social roles all influence drinking patterns (Collins \& McNair, n.d.; Herd \& Grube, 1996). Peindl (1992) in an unpublished doctoral dissertation cited in Lucas et al. (2003) found that African American women were more likely to continue drinking during pregnancy. Ockene et al. (2002) was the only study identified that indicated the rate of spontaneous cessation among pregnant African American/Black women. In this study $80 \% \quad(57$ of 71 respondents) of the Black women in the study spontaneously quit drinking. Okene et al. suggested that "the women who gave up alcohol may have been light or moderate alcohol users, rather than addicted" (p. 157). No other study was found that discussed possible reasons for cessation.

There is a need to gain more understanding about factors that influence abstinence from alcohol use during pregnancy among women who self identify as African American or Black. For simplicity in describing participants the term Black will be used which includes those who self identified as African American, Black, or mixed race. There were two primary focuses for our study. One was to identify factors that influence the intention to quit drinking alcohol during pregnancy. The second was to investigate the differences between Black women who quit drinking during pregnancy and those who continue to drink. Ajzen's (1991) theory of planned behavior provided a framework to address these two issues.

Ajzen postulates that intention to engage in a behavior is dependent upon (a) one's attitude toward the behavior, (b) the impact of subjective norms, and (c) perceived control - that is, the perceived ability to execute the behavior. Figure 1 shows a modified schematic of the theory of planned behavior applied to abstention from alcohol during pregnancy. 


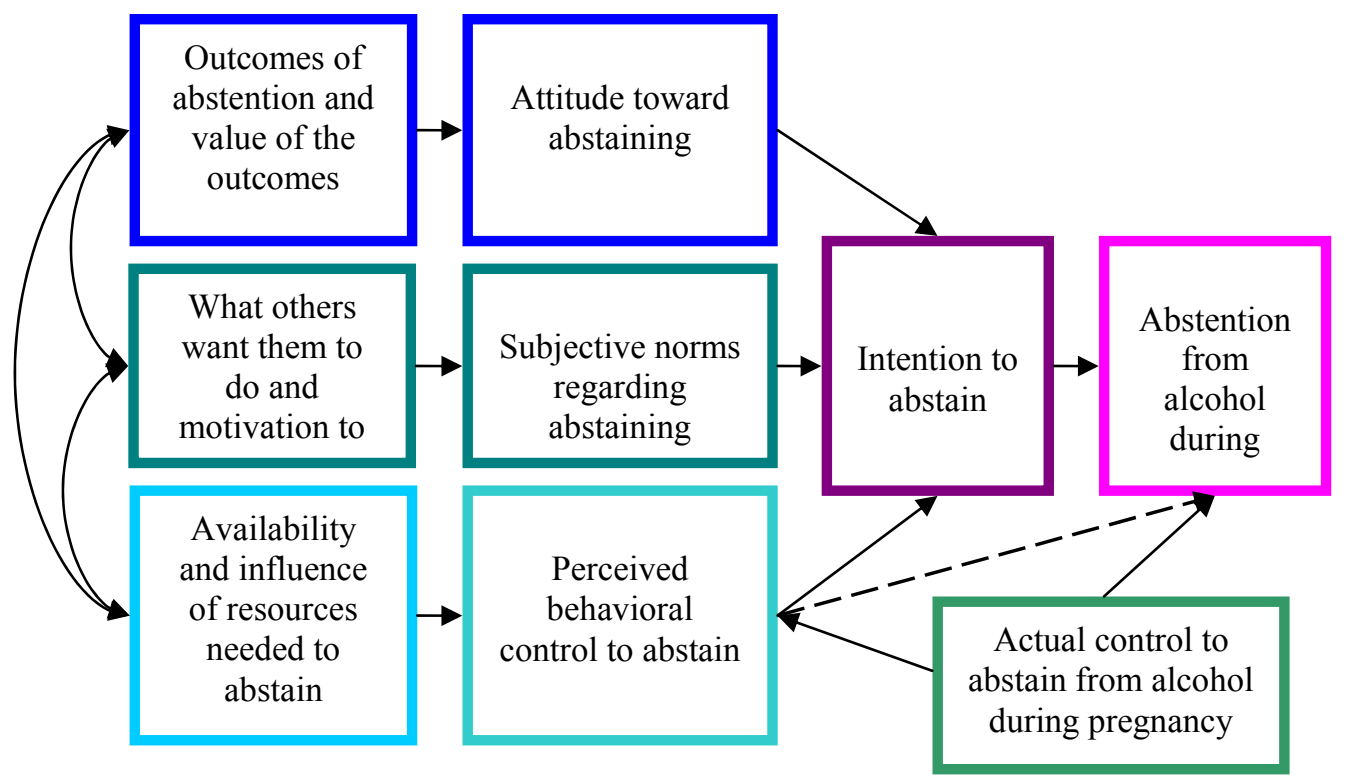

Figure 1

The theory of planned behavior applied to abstention from alcohol during pregnancy. Based on Ajzen (2002).

\section{Methodology \\ Design Overview}

This cross-sectional study among Black pregnant women examined factors influencing their intention to quit drinking alcohol while pregnant. Participants included in this study were Black pregnant women 18 to 45 years old who attended Women Infants and Children (WIC) clinics or Black Infant Health programs in Riverside and San Bernardino communities. Following, the methodology recommended by Ajzen (2002) the study had two phases: a qualitative phase designed to elicit salient beliefs regarding drinking alcohol while pregnant and a quantitative phase that examined how those beliefs related to the behavior through attitude, subjective norm and perceived control regarding the behavior.

\section{Qualitative Design}

The qualitative process included the use of openended questions with four focus group participants to elicit: (a) beliefs associated with outcomes of quitting drinking alcohol during pregnancy; (b) the individuals or groups of people who would or would not support them in their attempt to quit; and (c) any factors or circumstances that would influence quitting drinking alcohol during pregnancy.

\section{Subject Recruitment for the Qualitative Study}

Subject Recruitment. Recruitment flyers were distributed at $\mathrm{Ob} / \mathrm{Gyn}$ and WIC clinics where Black women accessed services. An Outreach worker was involved in the recruitment process. Recruitment was facilitated by offering a twenty-dollar gift certificate to focus group participants. A convenience sampling technique was utilized to solicit volunteers for the study who met the inclusion criteria for the study.

\section{Study}

\section{Data Collection for the Qualitative}

The purpose of the study and the consent form was reviewed prior to the start of any focus groups. Each focus group participant gave signed consent for participation. At the 
beginning of each focus group session written responses were gathered regarding factors relating to Black pregnant women quitting drinking during pregnancy. This written response was followed by a dialogue from each participant which was tape recorded. At the end of each session, a twenty-dollar gift certificate was given to each participant. The information gathered from each group was transcribed, sorted for specific information and utilized to construct the questionnaire for quantitative data collection, using Ajzen's 2002 conceptual and methodological guidelines.

\section{Study \\ Data Analysis for the Qualitative} Written responses, gathered from the focus group, were obtained from 14 of 22 participants. The 14 written responses and the transcribed dialogue from the focus groups resulted in 22 outcome beliefs, 23 normative beliefs, and 19 control beliefs which were the basis for the quantitative survey.

\section{Quantitative Design}

The quantitative design resulted in the development and analysis of a five-page survey. Using the focus group information from the qualitative study the quantitative questionnaire was developed based on Ajzen's (2002) guidelines.

\section{Subject Recruitment for the Quantitative Study}

Recruitment flyers were distributed at Black Infant Health sites and WIC clinics where Black women access perinatal services. A convenience sampling technique was utilized to solicit volunteers for the study who met the inclusion criteria for the study. In addition, participants were given a five-dollar gift certificate once surveys were completed.

\section{Study}

Instrumentation for the Quantitative

The questionnaire assessed all the variables listed in Figure 1. The survey also included questions regarding drinking patterns and questions to ascertain the demographics of the study participants.

\section{Study}

\section{Data Collection for the Quantitative}

The second phase of data collection used the questionnaire developed from the focus group process. The purpose of the study was explained to those who volunteered to participate and the questionnaire was distributed to women agreeing to participate and who were attending the Black Infant Health and Women Infant and Children (WIC) classes on the days designated for data collection. Respondents were informed that consent to participate in the study was established by completing the survey. To encourage honesty in survey responses, respondents were informed that no identifying information was included in the survey, therefore, the survey responses could not be tied back to any particular respondent. In addition, respondents were instructed not to include their names on the questionnaire. As an incentive, women received a five-dollar gift certificate upon completion of the survey.

\section{Study}

Data Analysis for the Quantitative

Responses to the questionnaire were entered into the Statistical Package for the Social Sciences (SPSS) for analysis. Surveys were excluded from the analysis if they were less than $80 \%$ complete and if the participant failed to meet inclusion criteria for alcohol use prior to or during pregnancy. Of the 179 collected a total of 148 met the inclusion criteria. Women who reported never having consumed alcohol were excluded from the analysis. Frequency statistics were done on all variables. Missing values were imputed with the expectation maximization algorithm for cases not missing more than 20\% of responses. All available variables were used for imputation in accordance with Schafer and Graham's (2002) recommendations. Due to low participant responses for normative beliefs only 5 of the 23 normative beliefs, identified via the focus groups, were included in the quantitative analysis.

Several questions were included in the survey to identify intention, attitude, subjective norm, and perceived control. Cronbach's alpha were calculated for the multiple questions regarding intention, attitude, subjective norm, and 
perceived control to determine the internal consistency on the questions. A multiple regression was run for the theory of planned behavior variables to determine which elements of the theory predict the intention to quit. The theory of planned behavior is based on expectancy value models which require measurement of two variables for each salient belief underlying the attitude, subjective norm and perceived control and that products be formed from each of these pairs. For example, each outcome belief is multiplied times the value of that outcome. However, the theory also suggests that the beliefs and values can be scaled by adding or subtracting a constant prior to multiplying the two. For example, if the outcome value had been measured on a scale running from 1 to 7, 4 might be subtracted from the value chosen by each respondent to yield a value score running from -3 for a rating of a negative valued outcome to +3 for a positively valued outcome. Since different scaling procedures give different results when the product terms are formed, Ajzen (2006) recommends an optimal scaling procedure which we used to maximize the correlation between the product terms and the intended prediction. Some researchers (e.g., French and Hankins, 2003) have objected to this use of optimal scaling as being overly complicated and theoretically unclearly justified but we elected to follow Ajzen's recommendations.

One problem with optimal scaling is that numerous scaling parameters can produce very similar correlations with the outcome variables and some of these may be positive and some negative. For example, in our study one outcome was that the mother would be healthier if she abstained from drinking. Participants rated the likelihood of that outcome and its value. The optimal scaling procedure resulted in scaling parameters of -27.499 for the outcome and 22.715 for its value. This produced a correlation of -.4204. However, if the scaling parameters were set to +30 and +18 the resulting correlation was +.4196 - a correlation with a difference in absolute magnitude from the optimally scaled amount of only .0008 but completely different in direction. Thus, different scaling parameters can produce essentially the same magnitude of correlation but different signs for the correlation. How should we choose the direction of the correlation? We chose the sign based on the simple correlations of the outcome likelihood by itself and the outcome value by itself with the attitude. In the example just discussed, both of these had positive correlations so we chose a positive sign. This process also had the advantage of making conceptual sense as one would expect that mothers who believed that abstention would make them more healthy would have a positive attitude toward abstention rather than the negative attitude that a strict adherence to the optimal scaling procedure would suggest. A similar procedure was followed for subjective norms and perceived control.

Correlations and regressions of the optimally scaled variables with their corresponding attitude, subjective norm, or perceived control scale was run. Collinearity statistics of the regression indicated that all of the variables were highly correlated. To correct the multicollinearity problem a factor analysis using a principle axis extraction and oblimin rotation was conducted on the following: (a) the optimally scaled outcome belief products, (b) the optimally scaled normative belief products, and (c) the optimally scaled control belief products.

Two techniques were used to identify differences in those who quit drinking and those who continued to drink during pregnancy. The mean values for the intention to quit, attitude, subjective norm, and perceived control were compared. In addition, a crosstabulation was done on categorical variables for the demographic questions and questions regarding drinking patterns. A Bonferroni adjustment was done to decide which variables were statistically significant.

\section{Results}

\section{Characteristics of Participants}

A total of 148 surveys were analyzed. The average age of the women completing the questionnaire was 26 , with the age range being 18 to 43. Half of the women (77) reported that they had completed high school. In addition, $62 \%(92)$ of the women report an annual family 
income of $\$ 20,000$ or less. Women were also asked to report when their baby was expected. Thirty-nine percent (58) indicated that they were expecting in four to six months, 32\% (47) expected their baby within the next three months, and 29\% (43) expected their baby to be born in more than six months.

A total of 21 women reported quitting drinking during their pregnancy. The remaining 127 women reported being current alcohol drinkers of which $16 \%$ (24) were heavy drinkers, $33 \%$ (49) average drinkers and $37 \%$ (54) light drinkers. Respondents were asked if they ever drank more than five drinks in one occasion. Just over half $(61 \%$ or 89$)$ reported drinking more than five alcoholic beverages, constituting binge drinking, at least once. Approximately half of the women $(55 \%$ or 81$)$ also reported being unable to remember what they did while under the influence of alcohol at least once. Finally, the overwhelming majority of women $(80 \%$, 119) indicated that they did not require an alcoholic beverage to get going in the morning.

Reliability of the Questionnaire Scales Internal consistencies (Cronbach's alpha) for the theory of planned behavior variables were .76, $.77, .70$ and .60 for intention, attitude, subjective norm, and perceived control, respectively.

\section{Predictors of Attitude}

Table 1 shows the structure matrix from the factor analysis of the 23 outcome variable products. Two underlying outcome factors were identified - abstention would improve the health of the baby and the mother and abstention would increase stress.

Table 1

Factor structure matrix for the optimally scaled outcome variables

\begin{tabular}{|c|c|c|}
\hline Outcome Variable & Health & Stress \\
\hline Healthier Baby & 0.91 & 0.31 \\
\hline Normal Pregnancy & 0.90 & 0.33 \\
\hline Baby Would Weight More & 0.90 & 0.25 \\
\hline I Would Be Healthier & 0.90 & 0.19 \\
\hline Baby Would Grow Bigger & 0.87 & 0.28 \\
\hline I Would Have a Better Family Life & 0.86 & 0.25 \\
\hline I Would Feel Better & 0.83 & 0.20 \\
\hline Baby Would Have No Birth Defects & 0.79 & 0.37 \\
\hline I Would Have More Money & -0.76 & -0.22 \\
\hline I Would Save Money & 0.76 & 0.17 \\
\hline I Would Have Ability to Focus & 0.74 & -0.01 \\
\hline I Would Eat More & 0.39 & 0.04 \\
\hline I would Get Stressed Out & 0.21 & 0.93 \\
\hline I Would Get Nervous & 0.18 & 0.91 \\
\hline I Would Get Impatient & 0.20 & 0.91 \\
\hline I would Get Snappy & 0.26 & 0.89 \\
\hline I would Get Angry & 0.32 & 0.85 \\
\hline I Would Throw Up More & 0.17 & 0.82 \\
\hline My Baby Might Be Premature & 0.28 & 0.78 \\
\hline I Would Get Withdrawal & -0.06 & -0.72 \\
\hline I would Crave a Drink & 0.22 & 0.71 \\
\hline My Baby Would Get Withdrawal & 0.18 & 0.62 \\
\hline
\end{tabular}

Note: Principle Axis Factor Analysis with Oblimin Rotation 
Regression of attitude toward quitting drinking during pregnancy on factor scores showed that when women believed that quitting drinking would result in better health outcomes for their baby and themselves they had a more positive attitude toward quitting $(\beta=.39, \mathrm{p}<.0005)$. When women believed that quitting would increase their stress they had a negative attitude toward quitting $(\beta=-.24, p=.001)$. See Figure 2 for the path model showing the Pearson correlation and factor scores for attitudes toward abstaining.

\section{Predictors of Subjective Norm and Perceived Control}

Factor analysis was unsuccessful in identifying a simple structure for the normative belief and perceived control variables probably due to a limited sample size and high multicollinearity. The simple Pearson correlation for normative beliefs and control beliefs did provide information relevant to one's intention to quit.
Appendix A shows a path model illustrating the association of the outcome, normative, and control belief optimally scaled scores with their corresponding theory of planned behavior variables. The path model shows that the five normative referents were highly predictive of the subjective norm to quit. All items for control beliefs were statistically significant predictors for perceived control to quit.

Differences between women who continued to drink and those who abstained when examining intention to quit drinking alcohol during pregnancy, based on the theory of planned behavior variables, significant differences between those who quit drinking during pregnancy and those who continued to drink were identified. Table 3 shows that mean intention to quit, as well as attitude, subjective norm, and perceived control in favor of quitting were all higher in those who had quit.

Table 3

\begin{tabular}{|c|c|c|}
\hline Theory Variable & $\begin{array}{c}\text { Mean for those who } \\
\text { quit }(n=21)\end{array}$ & $\begin{array}{c}\text { Mean for those who } \\
\text { continued to drink } \\
(n=127)\end{array}$ \\
\hline Intention & 6.45 & 5.02 \\
\hline Attitude & 6.12 & 5.15 \\
\hline Subjective Norm & 5.98 & 5.02 \\
\hline Perceived Control & 6.01 & 4.91 \\
\hline
\end{tabular}

Note. Means in the same row all differ at $\mathrm{p}<.01$

Women who continued to drink during pregnancy exhibit drinking patterns associated with problem drinking and/or addiction as shown in Table 4. It was also found that women who quit were closer to the end of their pregnancy. The following percentages represent the expectant due dates comparing those who quit vs. those who continued to drink, respectively: a) three or less months from now $(76 \%$ vs. $24 \%)$, b) four to six months ( $42 \%$ vs. $58 \%)$, and c) more than six months (33\% vs. $67 \%)$. 
Table 4

Differences in drinking patterns between those who quit and those who continue to drink $(N=148)$

\begin{tabular}{|c|c|c|}
\hline Drinking Patterns & Quit & Continued to Drink \\
\hline \multicolumn{3}{|c|}{ Ever drink more than 5 drinks in a day $\left(\chi^{2}=8.91, p=.003\right)$} \\
\hline Yes & $34 \%(50)$ & $66 \%(98)$ \\
\hline No & $61 \%(90)$ & $39 \%(58)$ \\
\hline \multicolumn{3}{|c|}{ Ever drank alcohol and could not remember $\left(\chi^{2}=9.71, p=.002\right)$} \\
\hline Yes & $36 \%(53)$ & $64 \%(95)$ \\
\hline No & $62 \%(92)$ & $38 \%(56)$ \\
\hline \multicolumn{3}{|c|}{ Ever need an alcoholic drink in the morning $\left(\chi^{2}=11.24, p=.002\right)$} \\
\hline Yes & $21 \%(31)$ & $79 \%(117)$ \\
\hline No & $57 \%(84)$ & $43 \%(64)$ \\
\hline
\end{tabular}

\section{Summary of Result Findings}

All three variables of the theory of planned behavior predicted intention to quit drinking alcohol. The correlation for attitude was $.61(\mathrm{p}=$ $.000)$ followed closely by perceived control .60 $(\mathrm{p}=.000)$. The subjective norm also had significant correlation with the intention to quit drinking alcohol during pregnancy $.56 \mathrm{c}=$ $.000)$. Once the correlation values were corrected for attenuation the values for each theory variable were $.77, .80$, and .89 for subjective norm, attitude, and perceived control respectively, indicating that perceived control best predicts intention. Calculations of attenuation corrected correlations used the Cronbach Alpha's values of each scale as estimates of reliability and used the standard formula as found in StatSoft, Inc. (2006) among other places. Attitude was best predicted by the underlying factor of beliefs associated with improved health $.39(\mathrm{p}=.000)$. All normative beliefs predicted the subjective norm well. Resources to reduce stress and increase one's self efficacy in quitting best predict perceived control. The R2 for the multiple regression, indicating how effectively the theory of planned behavior variables predict intention to quit was $.55(\mathrm{p}=.000)$. In addition, significant differences were found between the drinking patterns of women who quit and those who continued to drink.

\section{Discussion}

The aim of this study was to apply the theory of planned behavior methodology to identify factors that influence the intention of pregnant Black to quit drinking alcohol. The findings support the theory of planned behavior (Ajzen, 1991) as the direct measure variables were all significantly correlated with intention to quit drinking. The results in this study indicated that attitude, subjective norm, and perceived behavioral control account for $55 \%$ of the variance in intention. This compares with $41 \%$ found in McMillian and Conner's (2003) theory of planned behavior study which examined intention to quit drinking among college students.

This study is not without its limitations. The focus group and the questionnaire results were based on self reports. It is possible that the self reports underreported alcohol use or over reported abstinence, which is a limitation to the study. However, other studies have shown self reports regarding alcohol use to be valid (Brady, Gold, Killeen, Tyson, and Simpson, 2003; Del Boca and Darkes, 2003; and Midanik, 1988).

A further limitation was that the variables for subjective norm and perceived control were highly intercorrelated and factor analysis was unable to identify underlying factors for these variables. An increased sample size may have 
yielded stable factors for normative and control beliefs.

The convenience sampling technique could have recruited study participants who, for various reasons, skewed results. In addition, incentives provided to participants may have recruited individuals simply because of the desire to receive the incentive.

This study, however, has provided considerable information which can augment current literature on the use of the theory of planned behavior in predicting intention for abstention from alcohol use. This study also provides additional information on factors related to drinking patterns associated with Black pregnant women.

Information gained could be used to develop interventions geared toward assisting Black pregnant women in quitting drinking during pregnancy. Respondents who believed that an improvement in health would result for both themselves and their baby had a more positive attitude toward abstention. Putting this together with the finding that increased perceived control over abstention went with having information about the bad things that would happen to their baby and seeing things about the effect of drinking on their baby provides a strong argument for emphasis on health in programs to increase abstinence during pregnancy. Such emphasis should include improved health for the mother and the baby, decreased risk for negative pregnancy related outcomes, and decreased risk for negative health outcomes later in the life of the baby.

Another finding indicated that the women believed that an outcome of quitting would be increased stress which was negatively correlated with the attitude toward quitting. This is particularly interesting when put together with the fact that among the best predictors of perceived control were availability of ways to reduce stress in the environment and ways to stop stressing. Interventions should highlight that quitting drinking could actually decrease one's stress. Furthermore, the research suggests that Black women may be using alcohol as a stress reduction technique. Hence, it would be appropriate to teach women stress reduction technique alternatives. Finally, interventions should target increasing one's self-efficacy in the ability to quit.

\section{References}

Abel, E. (1995). An update on incidence of FAS: FAS is not an equal opportunity birth defect. Neurotoxicology Teratology, 17, 437-443.

Ajzen, I. (1991). The theory of planned behavior. Organizational Behavioral and Human Decision Processes, 50, 179-211.

Ajzen, I. (2002). Constructing a TpB questionnaire: Conceptual and methodological considerations. Retrieved May 3, 2004, from http://www.-unix.oit.umass.edu/ aizen/

Ajzen, I. (2006). Constructing a TpB questionnaire: Conceptual and methodological considerations. Retrieved March 20, 2006, from http://www.-unix.oit.umass.edu/ Ajzen/

Caetano, R., Clark, C., \& Tam T. (1998). Alcohol consumption among racial/ethnic minorities. Alcohol Health \& Research World, 22, 233-242.

Checky, L. (n.d.). Fetal alcohol syndrome. Retrieved November 12, 2004, from http://www.tchpeducation.com/General\%20interest/fetal\%20alcohol\%syndrome

Collins, L., \& McNair, L. (n.d.). Minority women and alcohol use. Retrieved April, 14, 2004, from http://www.niaaa.nih.gov/publications/arh26-4/251-256.htm

Cosden, M., \& Peerson, S. (1997). Effects of prenatal drug exposure on birth outcomes and early child development. Journal of Drug Issues, 27, 525-545.

Darlington, R. (n.d.). Factor analysis. Retrieved April 25, 2006, from http://comp9.psych.cornell.edu/Darlington/factor.htm

French, D. P., \& Hankins, M. (2003). The expectancy-value muddle in the theory of planned behavior and some proposed solutions. British Journal of Health Psychology, 8(1), 37.

Gittler, J., \& McPherson, M. (1990). Prenatal substance abuse. Children Today, 19(4), 3-9. 
Graves, K. (2002). Alcohol preference among pregnant Native American and African American urban women. Retrieved November 16, 2004, from http://www.eurekalert.org/pub_releases/200202/ace-apa020802.php

Herd, D., \& Grube, J. (1996). Black identity and drinking in the US: A national study. Addiction, 91, 845859.

Hutchins, E. (1997). Drug use during pregnancy. Journal of Drug Issues, 27, 463-486.

Information Technology Services. (2004, May). General FAQ \#25 handling missing or incomplete data. Retrieved April 25, 2006, from http://www.utexas.edu/its/rc/answers/general/gen25.html

Lucas, E., Goldschmidt, L., Day, N. (2003, November). Alcohol use among pregnant African American women. Health and Social Work, 28, 273-284.

May, P., \& Gossage, P. (2001). Estimating the prevalence of FAS: A summary. Retrieved November 14, 2004, from http://www.niaaa.nih.gov/publication/arh25-3159-167.pdf

National Center on Addition and Substance Abuse at Columbia University. (2000). Missed opportunity: National survey of primary care physicians and patients on substance abuse. Retrieved November 16, 2004, from http://www.casacolumbia.org

National Institute on Alcohol Abuse \& Alcoholism. (1994). Alcohol and minorities. Retrieved November 14, 2004, from http://www.niaaa.nih.gov/publications/aa23.htm

Ockene, J., Ma, Y., Zapka, J., Pbert, L., Goins, K., \& Stoddard, A. (2002). Spontaneous cessation of smoking and alcohol use among low-income pregnant women. American Journal of Preventive Medicine, 23, 150-159.

O'Connor, B. (2000). SPSS and SAS programs for determining the number of components using parallel analysis and Velicer's MAP test. Behavior Research Methods, Instruments, \& Computers, 32, 396-402.

Ondersma, S., Simpson, S., Brestan, E., \& Ward, M. (2000). Prenatal drug exposure and social policy: The search for an appropriate response. Child Maltreatment, 5(2), 93-108.

Ostrea, E., Brady, M. Gause, Raymundo, S., \& Stevens, M. (1992). Drug screening of newborns by meconium analysis: A large scale, prospective, epidemiologic study. Pediatrics, 89, 107-113.

Pirie, P., Lando, H., Curry, S., McBride, C., \& Grothaus, L. (2000). Tobacco, alcohol, and caffeine use and cessation in early pregnancy. American Journal of Preventive Medicine, 18, 54-61.

StatSoft, Inc. (2006). Electronic statistics textbook. Tulsa, OK: Author. Retrieved April 27, 2004, from http://www.statsoft.com/textbook/stathome.html

Substance Abuse and Mental Health Services Administration. (2003). Results from the 2002 national survey on drug use and health: National findings. Retrieved April 27, 2004, from http://www.drugabusestatistics.samhsa.gov/NHSDA/2k2NSDUH/Results/2K2results

Vega, W., Noble, A., Kolody, B., Porter, P., Hwang, J., \& Bole, A. (1992). Profile of alcohol and drug use during pregnancy in California. The New England Journal of Medicine, 329, 850-854.

\section{Acknowledgement}

This research was conducted in conjunction with support from the Riverside and San Bernardino counties, Department of Public Health, Black Infant Health Programs and Women Infant and Children programs. We are appreciative of the support received by these programs and the dedicated staff that helped make this research possible. 


\begin{tabular}{|l|l|}
\hline Author Information \\
Tamarra Jones, DrPH Candidate \\
Loma Linda University \\
School of Public Health \\
Loma Linda, CA 92350 \\
Ph.: 702-349-7602 \\
E-Mail: tamarrajones@hotmail.com \\
Naomi Modeste, DrPH* \\
Loma Linda University \\
School of Public Health \\
Loma Linda, CA 92350 \\
Barbara Anderson, DrPH, CNM, CHES \\
Seattle University College of Nursing \\
Seattle, WA 98122 \\
Jerry Lee, PhD \\
Loma Linda University \\
School of Public Health \\
Loma Linda, CA 92350 \\
V. Joyce Lim, DrPH \\
Loma Linda University \\
School of Public Health \\
Loma Linda, CA 92350 \\
* corresponding author
\end{tabular}




\section{Appendix A}

Path model showing how the theory of planned behavior components relate to the intention to quit drinking alcohol. $\mathrm{r}=$ Pearson correlations for the paired variables. The numbers on the paths to intentions are standardized regression coefficients and their statistical significance in parenthesis. The bold italicized numbers are the Pearson correlations corrected for attenuation.

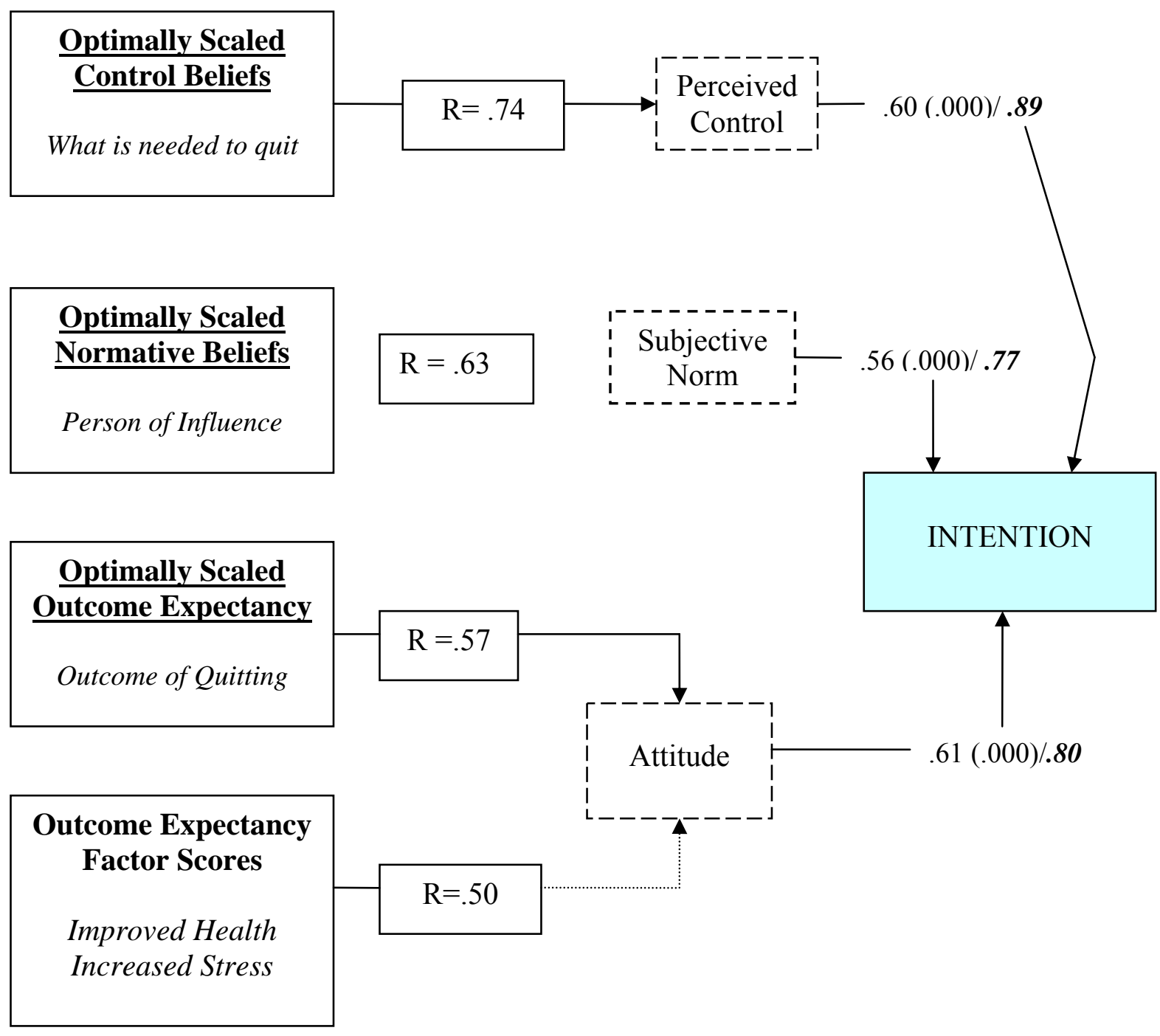




\section{Appendix A}

\section{Related Tables}

\begin{tabular}{|l|c|c|}
\hline \multicolumn{1}{|c|}{ Optimally Scaled Control Beliefs } & $\mathrm{r}$ & $\mathrm{p}$ \\
\hline What is needed to quit & 0.67 & .000 \\
\hline Finding ways to reduce the stress in my environment & 0.64 & .000 \\
\hline Places to go where people don't drink & 0.63 & .000 \\
\hline Information about the bad things that will happen to my baby if I keep drinking & 0.61 & .000 \\
\hline Ability to see things about the effect of drinking on my baby & 0.61 & .000 \\
\hline Having will power & 0.60 & .000 \\
\hline Having self discipline & 0.59 & .000 \\
\hline Ability to avoid seeing alcohol advertisements & 0.59 & .000 \\
\hline Finding ways to stop stressing & 0.57 & .000 \\
\hline Ability to go to church & 0.57 & .000 \\
\hline Things to help keep me occupied & 0.53 & .000 \\
\hline Encouragement from others & 0.52 & .000 \\
\hline Having positive people around me & 0.49 & .000 \\
\hline Having someone to support me in stopping & 0.48 & .000 \\
\hline Having a buddy who is trying to stop & 0.43 & .000 \\
\hline God's help in quitting & 0.42 & .000 \\
\hline Booklets and pamphlets about how to quit & 0.37 & .000 \\
\hline Classes to help me quit & 0.33 & .000 \\
\hline An alcohol rehab program & 0.32 & .000 \\
\hline Alcoholics Anonymous &
\end{tabular}

\begin{tabular}{|c|c|c|}
\hline \multicolumn{3}{|c|}{ Optimally Scaled Normative Beliefs } \\
\hline Person of Influence & $\mathrm{r}$ & $\mathrm{p}$ \\
\hline My friends who care about me & 0.48 & .000 \\
\hline Mother & 0.46 & .000 \\
\hline Husband/boyfriend & 0.46 & .000 \\
\hline Baby's daddy & 0.46 & .000 \\
\hline The people who helped raise me & 0.41 & .000 \\
\hline
\end{tabular}




\section{Appendix A}

\section{Related Tables}

\begin{tabular}{|c|c|c|}
\hline \multicolumn{3}{|l|}{ Optimally Scaled Outcome Expectancy } \\
\hline Outcome of quitting & $\mathrm{r}$ & $\mathrm{p}$ \\
\hline I would have a better family life & 0.45 & .000 \\
\hline My baby would grow bigger & 0.45 & .000 \\
\hline My baby would weight more at birth & 0.44 & .000 \\
\hline My baby would be healthier & 0.44 & .000 \\
\hline I would have a normal pregnancy & 0.44 & .000 \\
\hline I would be healthier & 0.42 & .000 \\
\hline I would feel better & 0.41 & .000 \\
\hline My baby will turn out alright (no birth defects) & 0.38 & .000 \\
\hline I would crave a drink of alcohol & -0.32 & .000 \\
\hline I would get withdrawal & -0.30 & .000 \\
\hline I would be impatient & -0.30 & .000 \\
\hline My baby might go into withdrawal & -0.29 & .000 \\
\hline I would get stressed out & -0.28 & .000 \\
\hline I would get snappy & -0.28 & .000 \\
\hline My baby might be born premature & -0.26 & .001 \\
\hline I would get nervous & -0.26 & .002 \\
\hline I would get angry easily & -0.25 & .001 \\
\hline I would save money & 0.25 & .001 \\
\hline I would have more money to spend on other things & 0.24 & .002 \\
\hline I would throw up more & -0.24 & .002 \\
\hline I will be able to focus more & 0.23 & .003 \\
\hline I would eat more & 0.20 & .263 \\
\hline Factor Scores & $B$ & \\
\hline Improved Health & 0.39 & \\
\hline Increased Stress & -0.24 & \\
\hline
\end{tabular}

